\title{
O USO DE LIVRO DIDÁTICO E SISTEMA DE ENSINO NA CONCEPÇÃO DOS PROFISSIONAIS DA EDUCAÇÃO
}

Elba Geovana de Sousa Pinto; Mariana Padovan Farah Soares; Mayara Faria Miralha; Silvio Cesar Nunes Militão

Faculdade de Ciências e Tecnologia da UNESP - Campus de Presidente Prudente. PROGRAD-UNESP/PIBIC/FAPESP. Email: elbinha2@hotmail.com

\section{RESUMO}

Este trabalho, integrante de pesquisa maior, toma o caso particular de uma escola de ensino fundamental de um município paulista que mantém sistema apostilado de ensino privado na sua rede escolar. Teve como objetivo analisar a crescente tendência de adoção de sistemas de ensino instaurada no Estado paulista a partir de 2000, particularmente no que se refere à concepção dos profissionais da educação sobre a utilização das apostilas versus a utilização do livro didático. Para tanto, a pesquisa se valeu de levantamento e análise bibliográfica acerca da temática e realização de entrevistas semiestruturadas com 14 sujeitos. Os resultados mostram que tal parceria públicoprivada traz consequências indesejáveis para educação/escola pública, como o duplo pagamento por materiais didáticos, frágeis conceitual e pedagogicamente. Demonstra, sobretudo, a majoritária preferência dos sujeitos da pesquisa pelo uso do livro didático em detrimento do material apostilado que, na visão deles, "engessa" o trabalho pedagógico do professor.

Palavras-chave: Ensino Fundamental; Livro Didático; Municipalização; Parceria público-privada; Sistema Apostilado de Ensino.

\section{INTRODUÇÃO}

O presente trabalho é decorrente de uma pesquisa maior, vinculada ao Programa Núcleo de Ensino da Faculdade de Ciências e Tecnologia da UNESP - Campus de Presidente Prudente, desenvolvida no ano de 2012 por alunos bolsistas do curso de Pedagogia da referida instituição.

O trabalho em tela teve por objetivo precípuo analisar a recente e crescente tendência de adoção de sistemas apostilados de ensino instaurada no Estado de São Paulo na contemporaneidade, particularmente no que se refere à concepção dos profissionais da educação sobre a utilização das apostilas versus a utilização do livro didático.

Para tanto, a pesquisa proposta, de natureza qualitativa, se valeu de levantamento e análise bibliográfica acerca da temática em estudo e da realização de entrevistas semiestruturadas. Dessa maneira, foram entrevistados 8 professores, 5 gestores e 1 Dirigente Municipal de Educação, num total de 14 sujeitos entrevistados. Em consonância com as normas do Comitê de Ética em Pesquisa, neste estudo os sujeitos que participaram da pesquisa têm os seus nomes preservados, sendo representados por letras, de $\mathrm{A}$ até $\mathrm{O}$. 


\section{MUNICIPALIZAÇÃO dO ENSINO FUNDAMENTAL NOS MUNICíPIOS PAULISTAS: BREVE CONTEXTUALIZAÇÃO.}

O vertiginoso e generalizado processo de municipalização do ensino fundamental em curso no Estado de São Paulo, fruto da explícita ação municipalista do governo estadual paulista combinada com os efeitos práticos da corrente política de Fundos, trouxe aos municípios paulistas novas e crescentes demandas educacionais. A partir da década de 1990, o governo federal passou a implementar um amplo programa de descentralização, transferindo ao nível estadual a gestão e reordenação das políticas educacionais. Nesse sentido, o Fundo de Manutenção e Desenvolvimento do Ensino Fundamental e de Valorização do Magistério (FUNDEF) foi um dos mecanismos utilizados para a fomentação e financiamento da municipalização. Durante o FUNDEF, que esteve em vigência de 1997 a 2006, 446 cidades do Estado de São Paulo municipalizaram o Ensino Fundamental, totalizando 567 cidades durante o tempo de vigor do Fundo. A combinação do FUNDEF com a política municipalista do governo paulista gerou, assim, um dos processos mais radicais de municipalização do ensino fundamental já vivenciados no Brasil.

Findado o FUNDEF, no final de 2006, a política de Fundos para o financiamento da educação brasileira teve continuidade com a criação do Fundo de Manutenção e Desenvolvimento da Educação Básica e Valorização dos Profissionais da Educação (FUNDEB), atual fundo em vigor (2007-2020) e que abrange todas as etapas e modalidades de ensino que compõem a Educação Básica. Em tempos de vigência do FUNDEB, dos 645 municípios paulistas 641 acabaram por aderir à municipalização do ensino fundamental (MILITÃO, 2012).

Com a incorporação do ensino fundamental, no todo ou em parte, os municípios paulistas ampliaram suas redes de ensino e passaram a ter novas responsabilidades e a vivenciar outras experiências educacionais. Carentes de estruturas materiais, físicas, humanas, financeiras, administrativas e pedagógicas para implantar políticas educacionais e dar continuidade a elas, sem experiência/preparo para gerir o Ensino Fundamental e sem contar com a devida assistência por parte do governo estadual para materializar a municipalização, os municípios paulistas passaram a buscar, cada vez mais, alternativas/apoio no setor privado para o atendimento das novas e crescentes demandas educacionais assumidas (ARELARO, 2007; OLIVEIRA et al, 2006).

Num quadro de responsabilidades educacionais ampliadas e despreparo técnico, generaliza-se pelo território paulista o estabelecimento de inúmeras parcerias educacionais entre 
as prefeituras paulistas e a esfera privada, sendo a aquisição dos chamados "sistemas apostilados de ensino privados" a mais frequente delas.

\section{LIVRO DIDÁTICO X SISTEMA APOSTILADO DE ENSINO: A CONCEPÇÃO DOS PROFISSIONAIS DA EDUCAÇÃO}

As parcerias entre prefeituras paulistas e as empresas privadas (Anglo, COC, Objetivo, Positivo, entre outras) vem crescendo, sendo que 161 dos municípios paulistas - a maioria deles de pequeno porte - já haviam adotado o sistema apostilado até o ano de 2007 para a educação infantil e ensino fundamental, segundo levantamento realizado por Adrião et (2009).

Entretanto, os municípios paulistas recebem livros didáticos gratuitos disponibilizados pelo governo federal por meio do Programa Nacional do Livro Didático (PNLD). Tal programa, criado em 1985 no âmbito do ensino fundamental, se estendeu posteriormente para o ensino médio e para a educação de jovens e adultos, todos executados pelo Fundo Nacional de Desenvolvimento da Educação (FNDE).

Cumpre esclarecer que os materiais didáticos dos sistemas apostilados de ensino privados, crescentemente adotados pelos municípios paulistas, custam em torno de $\mathrm{R} \$ 150,00$ por aluno/ano e são financiados pelos recursos municipais advindos do FUNDEB, os quais poderiam ser aplicados em outros fatores/insumos que concorrem para a melhoria da qualidade educacional local.

O quadro 1 revela a opinião dos entrevistados a respeito do material didático fornecido pela empresa privada de "apostilamento" às escolas de ensino fundamental do município contemplado pelo estudo. 
Quadro 1. Qual sua opinião sobre o material didático do sistema apostilado de ensino?

\begin{tabular}{|l|r|r|}
\hline \multicolumn{2}{|l|}{} \\
\hline Categorias & Freq. & $\%$ \\
\hline Possui conteúdo fraco/desinteressante/erros & 5 & 18,51 \\
\hline Tem que ser complementado com outros conteúdos/atividades & 5 & 18,51 \\
\hline É bom/gosto do material & 5 & 18,51 \\
\hline Faço adaptações para adequar à realidade dos alunos & 2 & 7,40 \\
\hline Pulo o que não é significativo para o aluno & 2 & 7,40 \\
\hline É um material “fechado" & 1 & 3,70 \\
\hline Tira a autonomia do professor & 1 & 3,70 \\
\hline É tradicionalista & 1 & 3,70 \\
\hline Os conteúdos são bem segmentados & 1 & 3,70 \\
\hline Diminui bastante o trabalho do professor & 1 & 3,70 \\
\hline É aprovado & 1 & 3,70 \\
\hline Já está relacionado às avaliações externas oficiais & 1 & 3,70 \\
\hline Facilita o controle/cobrança do trabalho & 1 & 3,70 \\
\hline TOTAL & $\mathbf{2 7}$ & $\mathbf{1 0 0}$ \\
\hline
\end{tabular}

Fonte: Pesquisa realizada (2012).

A maioria (10 ou 37,02\%) dos entrevistados destacou a fragilidade conceitual e pedagógica do material didático fornecido ao município, que possui conteúdo fraco, desinteressante e com erros e que precisa ser complementado com outros conteúdos e atividades, como ilustrado pelo relato: “Acho muito fraco. Tanto é que eu complemento os conteúdos/atividades com os meus alunos. A apostila é em 4 volumes e a última é tudo o que eu trabalhei no segundo bimestre, então estou bem adiantada. Ontem mesmo eu e a outra professora encontramos vários erros nas apostilas." (ENTREVISTADO I, 2012).

Na avaliação de Adrião et al (2009, p. 808):

Essa baixa qualidade pode estar relacionada, em parte, ao fato das empresas oferecerem aos municipios materiais distintos daqueles que elaboram para suas próprias escolas ou para as escolas privadas que franqueiam seu material. Trata-se de ofertar às escolas públicas um material de menor custo e que não faça frente àqueles existentes nas escolas privadas do município, uma vez que, se assim fosse, poderia haver um relativo êxodo das matrículas para o setor público, estabelecendo-se, ineditamente, uma concorrência intra serviços oferecidos pela mesma empresa.

Cumpre esclarecer, também, que o conjunto de apostilas produzidas pelas diversas empresas privadas - diferentemente dos livros didáticos - não passam por qualquer avaliação técnica e pedagógica oficial, o que certamente concorre para a sua chegada nas escolas municipais com qualidade aquém do esperado. 
Em contraposição, 5 (ou 18,51\%) dos entrevistados admitiram gostar do material didático do sistema apostilado, considerado por eles bom, conforme exemplifica o seguinte trecho: "Eu acho que esse sistema [apostilado] é bom. Ele vem a calhar, vem com os conteúdos em ordem de segmento e é muito bom. Eu gosto muito" (ENTREVISTADO B, 2012).

Ainda, a respeito da opinião dos entrevistados acerca do material apostilado, outras respostas com maior frequência foram: faço adaptações para adequar à realidade dos alunos (2 ou $7,40 \%$ ) e pulo o que não é significativo para o aluno ( 2 ou 7,40\%).

Sobre a relação da empresa privada com a escola, com a equipe gestora e com os professores, os sujeitos da pesquisa apontaram que ela se dá majoritariamente através dos cursos de formação (6 ou 22,22\%) ou pela Internet/telefone $(14,81 \%)$, o que não distoa daquilo que também impera noutras parcerias sistemas de ensino privados-municípios.

Quadro 2. Você prefere trabalhar com o material do sistema apostilado de ensino

\begin{tabular}{|l|c|r|}
\hline \multicolumn{3}{|c|}{ ou com o livro didático do PNLD? Por quê? } \\
\hline Categorias & Freq. & $\%$ \\
\hline Com o livro didático, que é melhor/dá mais liberdade de trabalho ao & 5 & 33,33 \\
\hline Indiferente & 5 & 33,33 \\
\hline Com o livro didático, desde que o professor seja bem formado & 1 & 6,66 \\
\hline Com o sistema apostilado, quando o professor não é bem formado & 1 & 6,66 \\
\hline Com o sistema apostilado, que é mais elaborado & 1 & 6,66 \\
\hline Com o sistema apostilado, pela formação para os professores & 1 & 6,66 \\
\hline Não respondeu & 1 & 6,66 \\
\hline TOTAL & $\mathbf{1 5}$ & $\mathbf{1 0 0 , 0}$ \\
\hline
\end{tabular}

Fonte: Pesquisa realizada (2012).

Pelo quadro 2, é possível constatar que os sujeitos da pesquisa, majoritariamente (6 ou 39,99\%), preferem trabalhar com o livro didático do PNLD, sobretudo por ser este um instrumento pedagógico melhor e que permite maior liberdade de trabalho ao professor. Inversamente, somente 2 (13,32\%) dos depoentes afirmaram predileção pelo material do sistema apostilado de ensino, considerado por eles mais elaborado e capaz de suprir a má formação inicial docente. Um outro (6,66\%) entrevistado manifestou preferência pelo sistema apostilado pela oferta dos cursos de formação para os professores. Chama-nos a atenção, ainda, o fato de um número significativo de entrevistados (5 ou 33,33\%) ter se manifestado de maneira indiferente a tal questionamento.

Sobre a preferência pelo uso do livro didático, um entrevistado justificou: "Eu gosto mais do livro didático, porque eu acho que eu posso usar os temas dentro do conteúdo 
proposto pela escola, seguir uma linha, pois eu tenho um cronograma, eu posso alternar. Já o material apostilado ele não me dá essa liberdade" (ENTREVISTADO A, 2012). Outro sujeito assim relatou: "Eu prefiro o livro didático, porque eu acho que ele deixa um leque maior de opção de trabalho. Eu trabalho [em outro município] também, mas com o livro didático e não temos que trabalhar todo o conteúdo do livro. Tem coisa que você vê que não vai dar pra trabalhar e que você pode pular, pode ir e voltar, diferente do material apostilado" (ENTREVISTADO G, 2012).

Das falas dos entrevistados depreende-se que os sistemas apostilados de ensino, ao determinar conteúdos, tempos de trabalho, rotinas e metodologias de ensino e a avaliação, acaba por "engessar" o professor, restringindo seriamente sua autonomia de conceber/realizar sua prática pedagógica e retirando o próprio sentido do seu trabalho/papel (ADRIÃO, et al, 2009; CAÇÃO, 2011).

\section{CONSIDERAÇÕES FINAIS}

De acordo com os resultados da pesquisa realizada, constata-se que a compra do sistema apostilado de ensino privado possui alto custo, o que leva o poder público a deixar de investir noutros fatores que reconhecidamente contribuem para a melhoria da qualidade de educação, como por exemplo a valorização profissional docente e a diminuição do número de alunos por turma.

Tal "gasto" é certamente desnecessário, já que o MEC disponibiliza livros didáticos gratuitos aos municípios, cujo valor investido pelo governo federal é significativamente inferior ao praticado com os "apostilamentos" privados pela esfera municipal.

Mesmo de alto custo, os materiais didáticos (apostilas) comprados são via de regra distintos dos fornecidos para as escolas particulares, não passam por criteriosa avaliação oficial e ainda se impõe acima da realidade local/específica que desconhecem.

Por serem essencialmente prescritivos, acabam por "desqualificar" a profissão docente, bem como ignoram o tempo de aprendizagem de cada aluno, uma vez que as aulas são planejadas/determinadas externamente por outrem.

Por fim, conclui-se que os sujeitos da pesquisa preferem usar o livro didático em detrimento do material apostilado de ensino que, na visão dos profissionais da educação é frágil conceitual e pedagogicamente e acaba por "engessar" o trabalho pedagógico do professor. 


\section{REFERÊNCIAS}

ADRIÃO, Theresa et al. Uma modalidade peculiar de privatização da educação pública: a aquisição de "sistemas de ensino" por municípios paulistas. Educ. Soc. 2009, vol.30, n.108. p.799-818.

ARELARO, Lisete Regina Gomes. Formulação e Implementação das Políticas Públicas em Educação e as Parcerias Público-Privadas: Impasse Democrático ou Mistificação Política?. Educ. Soc., Campinas, 2007. v.28. n.100 - Especial. p. 899-919.

CAÇÃO, Maria Izaura. São Paulo faz escola? Da alienação do trabalho docente. Florianópolis: UFSC, 2011. Disponível em <www.5ebem.ufsc.br/trabalhos/eixo_05/e05c_t004.pdf>. Acesso em: 20 jun. 2012.

MILITÃO, Silvio. Cesar. Nunes. O FUNDEB e a municipalização do ensino fundamental em São Paulo: novo fundo, velhas tendências. EDUCAÇÃo: Teoria e Prática, vol. 22, n. 41, p. 145165, set./dez. 2012.

OLIVEIRA, C. et al. Conselhos Municipais de Educação: um estudo na região metropolitana de Campinas. Campinas, SP: Alínea, 2006. 